\title{
Do Consumer Demographics Affect Dynamic Price Markdowns of Seasonal Goods?
}

\author{
Aidin Namin, Ph.D. \\ Assistant Professor of Marketing \\ The University of Idaho, College of Business \& Economics
}

\begin{abstract}
In this research we investigate the consumer demographics impact on consumer strategic purchase behavior of seasonal goods. Our findings would be beneficial for retailers and firms in the fashion industry to help them decide how to do their price markdowns during the season. We develop different demographic segments as these segments react differently to price markdowns based on the factors that they have in common, and the elements which differentiates them. We use demographic factors to identify different market segments for seasonal products. We show that reducing the prices based on the expected response of different demographics segments in the market would help the retailer to plan the price markdowns in the seasonal goods industry, and also would help them in capturing the most out of different demographic segments in the market. Our findings can particularly be useful in terms of generating and managing demand, and selling the product in their best possible price.
\end{abstract}

Keywords: Dynamic pricing, Choice models, Consumer strategic behavior, Demographics, Marketing research, Consumer research

\section{INTRODUCTION}

The decisive factor regarding the seasonal (short life cycle) goods has always been their availability in a finite time horizon, which is usually accompanied by small (sometimes zero, for hotels for instance) salvage value by the end of time horizon. Focusing on fashion clothes, relatively long lead times makes capacity almost constant which can be increased at a high marginal cost. In other words we are facing fixed supply, in a limited period of time in fashion industry.

It may be in the interest of firms to decide on frequency and depth of price markdowns through a dynamic pricing mechanism to capture more profit, and at the same time minimize the over stock costs at the end of period. Obviously the retailer has to markdown the prices in order to not to face an excess inventory at the end of the period. There also has always been a risk of stock out as a result of uncertain and changing demand which may or may not end in less profit, and that may also need dynamic pricing tools to help them come up with the right and effective pricing decisions.

Previous research show that carrying fewer inventories would bring more profit to the firm at the end of the horizon (Soysal and Krishnamurthi 2012). Thinking of more than one fashion product in the seasonal time horizon made us think of how to capture the relationship between customer's strategic behavior as a response to price markdowns and the demographics that make the strategic behavior. We model the consumer strategic behavior from expectations of 
future prices and markdown in prices based on the demographic properties of the segment that they belong to.

The impact of demographics on consumer price sensitivity has been discussed in previous literature. Kim, Srinivasan, and Wilcox (1999) show that household level demographic data does not show that much of predictive validity in determining household price sensitivity. Hoch, Montgomery, and Rossi (1995) show that household demographics variables explain for the $67 \%$ of variation in price response. Up to our knowledge no research has not studied the relationship between consumer demographics and consumer price sensitivity for fashion goods. Following Soyal and Krishnamurthi (2012) model and Hoch Montgomery, and Rossi (1995) results we develop our hypotheses.

\section{LITERATURE REVIEW}

As Elmaghraby and Keskinocak (2003) categorize the pricing across markets, replenishing the inventory during the selling season is usually not possible because of the long procurement lead times in the fashion industry; which is also the case for most short-life-cycle products. From the perspective of dependency of demand over time, they note that since for the fashion goods the selling horizon is usually very short, customers do not get the chance to collect knowledge and learn about the product that is being supplied in the market, so there is not enough knowledge to impact the demand, as a result the demand stays independent of consumers knowledge over time.

Based on these two important facts, which are also the case for our research, it is obvious that the seller has a fixed inventory on hand and faces a pricing decision on the finite horizon (the season for example) to make the most of the products and also not face the stock out or excess inventory issues.

Pashigian (1988) focuses on clearance sales, and Pashigian and Bowen (1991) mention demand uncertainty and price discrimination as two hypothesis to explain pricing practices. With the assumption of consumer's myopic behavior; the following researches are done. Lazear (1986) assumes a number of customers arrive at each period and each know their reservation price which is unknown to the distributor. Feng and Gallego (1995) model the demand as time invariant Poisson process. This research was generalized by assuming the demand to be non homogeneous in the researches done by Bitran, Caldentey, and Mondschein (1998), Bitran and Mondschein (1997), and Zhao and Zheng (2000).

Focusing on fashion goods, Smith and Achabal (1998) study how inventory level for a seasonal good affects demand. Mantrala and Rao (2001) provide a Decision Support System to help the retailer with the optimal markdown pricing and initial inventory level. Gallego and van Ryzin (1994) show that an increase in inventory is followed by a decrease in price, also longer selling periods make the optimal price to rise while keeping the inventory level constant.

It has been shown that different patterns for prices may be seen if the price is allowed to move in both directions. Works by Lazear (1986), Bitran and Mondschein (1997), and Gallego and van Ryzin (1994) incorporate this finding. In this research since we are studying the mark down pricing and our basic assumption is the optimal price decreases over time.

In another stream of litreture some papers have focused on consumer's strategic behavior and consumer forward looking. Erdem and Keane (1996) present a structural dynamic choice model, also Erdem, Imai, and Keane (2003), and Hendel and Nevo (2006a) study scanner panel data. 
In this paper since we focus on seasonal goods. We may need to mention some literature done in this field through high tech products. Those type of products are similar to the seasonal goods because they both have declining pattern over the life-cycle of a product which makes consumers delay their purchase based on future expectation of cheaper prices in future. Researches in this field are done by Melnikov (2000), Song and Chintagunta (2003), and Nair (2007).Besanko and Winston (1990) show that strategic consumer behavior makes the firm to lower its prices.

Su (2007), Aviv and Pazgal (2008), Dasu and Tong (2008), and Cho, Fan, and Zhou (2006) find the factors that can explain early purchasing by some consumers even though prices are expected to be reduced in the future. Liu and van Ryzin (2008) show that under stocking for monopolist who faces strategic consumers might end up in more profits. Also dynamic pricing of seasonal goods had been studied by McAfee and te Velde (2007), and Sweeting (2008). The latter research show that early buying can be explained by some factors such as uncertainty about future prices and availability. From the aspect of the impact of stock out and product availability on demand previous research is done by Gönül and Srinivasan (1996), and Erdem Imai, and Keane (2003), Bruno and Vilcassim (2008), and Musalem et al. (2010)

Up to our knowledge no research has not studied the relationship between consumer demographics and consumer price sensitivity for fashion goods. We explain our theory and hypotheses formation in the nest section.

\section{THEORY AND HYPOTHESES}

In this paper we assume that consumers are rational and in each period they have an option to buy vs. not buy the product. In addition to being rational, we also assume that they show strategic behavior; meaning in each period they include their expectation of future prices when they decide to buy, not buy the product and based on that they maximize their utility function. Obviously consumers from less price sensitive demographics may choose to purchase earlier in the time horizon, while consumers from more price sensitive demographics may delay their purchase based on the type of strategic behavior that may exist in their demographics segment.

Since consumers are heterogeneous, in each period and based on their demographic background, they make their decision of purchasing vs. not purchasing.

From one side they make more utility waiting for lower prices through the time horizon, from the other side their utility is reduced as they delay their purchase and wait more for lower prices. Not only reduction in utility occurs because of having less time to "use" the product (because the product is seasonal), but also they also face the risk of stock out for the product. So they face a trade off, in our model we are trying to reveal how demographics play a rule in this forward looking behavior and how can firms use that in order to make their dynamic markdown pricing decision. Assuming consumer heterogeneity gives the retailer the chance to set the prices dynamically to capture different consumers from different demographics segments.

We are assuming there are a finite number of goods (N), N $>1$, and there exist only a single color for each good. Consumers who choose to purchase each product leave the market for "that" product but still have the choice of purchasing "other" products offered by the retailer. So the market for each product shrinks during time horizon. The consumer choice on different products is assumed to be independent from another (i.e. choosing to buy a specific product does not affect the consumer's choice of other products). In other words we are not allowing for substitutions and complementarily effects in our model. 
In general, sales increase in the periods where prices are marked down but decrease immediately after the markdown period.

In our model, we have focused on seven demographic variables, which are education of the head of the household, ethnic background, household annual income, household size (number of people in the household), employment status of head of the household, whether the household owns the home or not, and consumer's age.

In Table 1 to Table 6 different levels of each of the demographics variables are explained:

Table 1. Levels of head of household education

\begin{tabular}{ll}
\hline Level & Education \\
\hline Level 1 & Below high school \\
Level 2 & High school \\
Level 3 & College \\
Level 4 & Masters \\
Level 5 & PhD \\
\hline
\end{tabular}

Table 2. Levels of household ethnic background

\begin{tabular}{ll}
\hline Level & Race \\
\hline Level 1 & Black \\
Level 2 & white \\
Level 3 & Asian \\
Level 4 & Hispanic \\
Level 5 & other \\
\hline
\end{tabular}

Table 3. Levels of household annual income

\begin{tabular}{ll}
\hline Level & Income \\
\hline Level 1 & $\$ 0-\$ 19,999$ \\
Level 2 & $\$ 20,000-\$ 39,999$ \\
Level 3 & $\$ 40,000-\$ 69,999$ \\
Level 4 & $\$ 70,000-\$ 99,999$ \\
Level 5 & $\$ 100,000+$ \\
\hline
\end{tabular}

Table 4. Levels of household size (number of people in the household)

\begin{tabular}{ll}
\hline Level & Household size \\
\hline Level 1 & 1 \\
Level 2 & 2 \\
Level 3 & 3 \\
Level 4 & 4 \\
Level 5 & $5+$ \\
\hline
\end{tabular}


Table 5. Levels of head of the household employment status

\begin{tabular}{ll}
\hline Level & Employment status \\
\hline Level 1 & Unemployed \\
Level 2 & Part time \\
Level 3 & Full time \\
\hline
\end{tabular}

Table 6. Levels of household home ownership status

\begin{tabular}{ll}
\hline Level & Home ownership status \\
\hline Level 1 & Own \\
Level 2 & Rent
\end{tabular}

Having the demographic variables of our model defined and assuming that consumer's utility increases by purchasing the product in compare to not purchasing that, we continue by introducing the model.

Consumer $i$ 's indirect utility from consuming product $j$ at time $t$ is defined as Equation 1:

$$
\begin{aligned}
& U_{i j t}=\alpha_{j}+\beta_{i p} * p_{j t}+\beta_{i m} * d_{j t}+\beta \mathrm{edu} i \mathrm{t} * \mathrm{Edu}_{\mathrm{it}}+\beta \mathrm{eth}_{\mathrm{it}} * \mathrm{Eth}_{\mathrm{it}}+\beta \mathrm{inc}_{\mathrm{it}} * \mathrm{Inc}_{\mathrm{it}}+ \\
& \beta \mathrm{famit}_{\mathrm{it}} * \mathrm{Famit}_{\mathrm{it}}+\beta \mathrm{empmp}_{\mathrm{it}} * \mathrm{Empmp}_{\mathrm{it}}+\beta \mathrm{home}_{\mathrm{it}} * \text { Home }_{\mathrm{it}}+\beta \mathrm{age}_{\mathrm{it}} * \mathrm{Age}_{\mathrm{it}}+\varepsilon_{i j t}(1)
\end{aligned}
$$

The variables used in the model are defined as following:

$\alpha_{j}:$ Intrinsic utility for product $j$

$p_{j t}$ : Price of product $j$ at time $t$ (we are assuming $\mathrm{N}$ products to be available in the market)

$d_{j t}$ : Markdown dummy (i.e. whether the product was sold in full price/ markdown)

$\beta_{i p}, \beta_{i m}$ and $\beta$ age $e_{\mathrm{it}}$ : are price sensitivity, markdown sensitivity and age sensitivity parameters respectively

Eduit : Education dummy variables, the five levels of education will be covered by four dummies

Ethit : Ethnicity dummy variables, the five levels of ethnicity will be covered by four dummies

Incit : Income dummy variables, the five levels of will be covered with four dummies

Famit : Family size dummy variables, the five levels of family size will be covered with four dummy variables

Empit: Employment status dummy variables, the three levels of employment status will be covered by two dummy variables

Homeit : Home ownership status dummy variables, one dummy will cover for two levels of home ownership status.

Age ${ }_{i t}$ : Consumer age

$\varepsilon_{i j t}:$ Stochastic error term with zero mean

Study by Hoch Montgomery, and Rossi (1995), even though done on grocery goods, but still gives some insights on further research for different types of goods. They show education, owning a home and, smaller family size reduce the consumer price sensitivity for grocery shopping. They also show that black and Hispanic consumers are more price sensitive than the other ethnic groups. Having that insight we form our hypothesis for seasonal (i.e. fashion) goods. 
Normally fashion goods have more fans in the younger generation. When a new fashion cloth is launched into to the market (or sometimes even before that), a group of consumers already know about the product and waiting to purchase that. On the other hand the younger generation is not usually that wealthy, so they maybe have to wait for the price markdowns to reduce the price. One may ask which of the "age" and "income" effect makes the consumer to make the decision of purchasing early or late.

We except them both to have significant impact on consumer's choice to either postpone the purchase for the price to reduce more as buy it as full/almost full price, but since they are young are do care about the fashion it might be rational to assume that the effect of "age" is stronger than the effect of "income". With this discussion we can form out first hypothesis:

Hypothesis 1: Income level and age of the consumer both have significant impact on consumer's choice in the sense that, the more the income the less patient the consumer for price markdowns and the more the age the more patient the consumer for price markdowns. Between these two, we expect younger consumers with less income show less patience for the prices to go down and hence have a higher probability of buying at full/almost full price in compare to older consumers with higher incomes.

Fashion cloths are more considered as "luxury" goods and not really a need for the basic life a common person. Usually more educated people (faculty members, medical doctors etc) don't follow fashion clothing that much. Hence it would be rational to expect them to have less willingness to pay for the fashion clothes and so be more patient for the prices to be marked down. Based on this idea the second hypothesis is formed:

Hypothesis 2: the higher the education level of the household, the more patient them for the prices to go down (i.e. the greater the probability of purchase in the mark down price)

Research by Hoch Montgomery, and Rossi (1995) show that owning a larger, more expensive home would reduce the price sensitivity, and the explanation behind that is those households have more space to stockpile and keep the goods. For fashion goods the same explanation would not necessary hold because fashion goods normally do not take that much of space.

In that sense we have looked for other explanations that may connect these two, besides in this research owning a home is being studied not the size of the home owned. Based on that we argue that not all the home owners are from the educated level of society, but it would be rational to expect that home owners are form the high income level of society. With that intuitive assumption we would expect owning a home to have an impact more similar to the impact of having high income rather than having high levels of education on consumer strategic behavior for fashion goods. Based on what was discussed earlier we have formed out third hypothesis.

Hypothesis 3: owning a home makes the consumer less price sensitive for fashion goods. Having demographic data from a fashion retailer would help to test these hypotheses and explore the relationship between price markdowns and demographics variables.

\section{Research Contributions}

The model developed in this paper can be used in the fashion industry to give some insights on how to run the permanent markdown pricing based on the customer's demographics that each store faces according to where it is located. 
Also it helps the firm to identify the most influential demographics in the fashion industry, which would indeed be helpful is segmenting their customers.

And finally it would give some insights on the optimal level of inventory to keep in the season to reduce the inventory and stock out costs.

\section{LIMITATIONS AND FURTHER RESEARCH}

The most important limitation of this paper is "lack of data". Having no access to appropriate data did not let the author to test the hypothesis. Further empirical research would be a major step to explore those relationships in practice.

Another major further research would be studying the "online" markdown pricing for fashion sales and see if those are different from the "in store" sales. Demographics may have a different impact on consumer strategic behavior in online environment. One explanation for that could be different levels of access to information about the product offered by competitors at the time of purchase based on the different demographic group.

The third idea for further research could be studying price mark down combined with other "temporary" promotions. That would give insight to store managers on how to combine these different types of promotion together and take the benefit of that.

Another area for further research would be estimating the demand function to reduce its uncertainty; that would give very useful insights for segmentation and different price sensitivity levels from different segments in the market.

Finally the last further research idea would be allowing the consumer choice to be dependent to his choice for other products. In other words purchase of one product has the potential to impact the consumer choice for the rest. The degree of this dependency may also vary among different products.

\section{References}

Aviv, Y., \& Pazgal, A. (2008). Optimal pricing of seasonal products in the presence of forward-looking consumers. Manufacturing \& Service Operations Management, 10(3), 339-359

Besanko, D., \& Winston, W. L. (1990). Optimal price skimming by a monopolist facing rational consumers. Management Science, 36(5), 555-567.

Bitran, G. R., \& Mondschein, S. V. (1997). Periodic pricing of seasonal products in retailing. Management Science, 43(1), 64-79.

Bitran, G., Caldentey, R., \& Mondschein, S. (1998). Coordinating clearance markdown sales of seasonal products in retail chains. Operations research, 46(5), 609-624.

Bruno, H. A., \& Vilcassim, N. J. (2008). Research Note-Structural Demand Estimation with Varying Product Availability. Marketing Science, 27(6), 1126-1131.

Dasu, S., \& Tong, C. (2010). Dynamic pricing when consumers are strategic: Analysis of posted and contingent pricing schemes. European Journal of Operational Research, 204(3), 662-671.

Elmaghraby, W., \& Keskinocak, P. (2003). Dynamic pricing in the presence of inventory considerations: Research overview, current practices, and future directions. Management Science, 49(10), 1287-1309.

Erdem, T., Imai, S., \& Keane, M. P. (2003). Brand and quantity choice dynamics under price uncertainty. Quantitative Marketing and Economics, 1(1), 5-64.

Erdem, T., \& Keane, M. P. (1996). Decision-making under uncertainty: Capturing dynamic brand choice processes in turbulent consumer goods markets. Marketing science, 15(1), 1-20. 
Feng, Y., \& Gallego, G. (1995). Optimal starting times for end-of-season sales and optimal stopping times for promotional fares. Management Science, 41(8), 1371-1391.

Gallego, G., \& Van Ryzin, G. (1994). Optimal dynamic pricing of inventories with stochastic demand over finite horizons. Management science, 40(8), 999-1020.

Gönül, F., \& Srinivasan, K. (1996). Estimating the impact of consumer expectations of coupons on purchase behavior: A dynamic structural model. Marketing Science, 15(3), 262-279.

Hendel, I., \& Nevo, A. (2006). Measuring the implications of sales and consumer inventory behavior. Econometrica, 74(6), 1637-1673.

Hoch, S. J., Kim, B. D., Montgomery, A. L., \& Rossi, P. E. (1995). Determinants of store-level price elasticity. Journal of marketing Research, 17-29.

Kim, B. D., Srinivasan, K., \& Wilcox, R. T. (1999). Identifying price sensitive consumers: the relative merits of demographic vs. purchase pattern information. Journal of Retailing, 75(2), 173-193.

Lazear, E. P. (1984). Retail pricing and clearance sales (No. w1446). National Bureau of Economic Research.

Liu, Q., \& van Ryzin, G. J. (2008). Strategic capacity rationing to induce early purchases. Management Science, 54(6), $1115-1131$.

Mantrala, M. K., \& Rao, S. (2001). A decision-support system that helps retailers decide order quantities and markdowns for fashion goods. Interfaces, 31(3_supplement), S146-S165.

McAfee, R. P., \& Te Velde, V. (2006). Dynamic pricing in the airline industry. Forthcoming in Handbook on Economics and Information Systems, Ed: TJ Hendershott, Elsevier.

Melnikov, O. (2000). Demand for differentiated durable products: The case of the US computer printer market.

Manuscript. Department of Economics, Yale University.

Musalem, A., Olivares, M., Bradlow, E. T., Terwiesch, C., \& Corsten, D. (2010). Structural estimation of the effect of out-of-stocks. Management Science, 56(7), 1180-1197.

Nair, H. (2007). Intertemporal price discrimination with forward-looking consumers: Application to the US market for console video-games. Quantitative Marketing and Economics, 5(3), 239-292.

Pashigian, B. P. (1988). Demand uncertainty and sales: A study of fashion and markdown pricing. The American Economic Review, 936-953.

Pashigian, B. P., \& Bowen, B. (1991). Why are products sold on sale?: Explanations of pricing regularities. The Quarterly Journal of Economics, 1015-1038.

Smith, S. A., \& Achabal, D. D. (1998). Clearance pricing and inventory policies for retail chains. Management Science, 44(3), 285-300.

Song, I., \& Chintagunta, P. K. (2003). A micromodel of new product adoption with heterogeneous and forward-looking consumers: Application to the digital camera category. Quantitative Marketing and Economics, 1(4), 371-407.

Soysal, G. P., \& Krishnamurthi, L. (2012). Demand dynamics in the seasonal goods industry: An empirical analysis. Marketing Science, 31(2), 293-316.

Su, X. (2007). Intertemporal pricing with strategic customer behavior. Management Science, 53(5), 726-741.

Sweeting, A. (2008). Equilibrium price dynamics in perishable goods markets: The case of secondary markets for Major League Baseball tickets (No. w14505). National Bureau of Economic Research.

Zhao, W., \& Zheng, Y. S. (2000). Optimal dynamic pricing for perishable assets with nonhomogeneous demand. Management science, 46(3), 375-388.

Cho, M., Fan, M., \& Zhou, Y. P. (2009). Strategic consumer response to dynamic pricing of perishable products. In Consumer-Driven Demand and Operations Management Models (pp. 435-458). Springer US. 